\author{
Marquette University \\ e-Publications@Marquette
}

2014

\title{
Development of Analytical Models of T- and U-shaped Cantilever- based MEMS Devices for Sensing and Energy Harvesting Applications
}

\author{
Stephen M. Heinrich \\ Marquette University, stephen.heinrich@marquette.edu \\ M. T. Boudjiet \\ University of Bordeaux \\ D. Thuau \\ University of Bordeaux \\ P. Poulin \\ University of Bordeaux \\ C. Ayela \\ University of Bordeaux
}

See next page for additional authors

Follow this and additional works at: https://epublications.marquette.edu/civengin_fac

Part of the Civil and Environmental Engineering Commons

\section{Recommended Citation}

Heinrich, Stephen M.; Boudjiet, M. T.; Thuau, D.; Poulin, P.; Ayela, C.; and Dufour, Isabelle, "Development of Analytical Models of T- and U-shaped Cantilever-based MEMS Devices for Sensing and Energy Harvesting Applications" (2014). Civil and Environmental Engineering Faculty Research and Publications. 44.

https://epublications.marquette.edu/civengin_fac/44 


\section{Authors}

Stephen M. Heinrich, M. T. Boudjiet, D. Thuau, P. Poulin, C. Ayela, and Isabelle Dufour 


\title{
Development of analytical models of T- and Ushaped cantilever-based MEMS devices for sensing and energy harvesting applications
}

\author{
S.M. Heinrich \\ Department of Civil, Construction and Environmental Engineering \\ Marquette University \\ Milwaukee, WI \\ M.T. Boudjiet \\ Université de Bordeaux, IMS \\ Talence, France \\ D. Thuau \\ Université de Bordeaux, IMS \\ Talence, France \\ P. Poulin \\ Université de Bordeaux, CNRS \\ Centre de Recherche Paul Pascal \\ Pessac, France \\ C. Ayéla \\ Université de Bordeaux, IMS \\ Talence, France
}




\author{
I. Dufour \\ Université de Bordeaux, IMS \\ Talence, France
}

\begin{abstract}
Dynamic-mode cantilever-based structures supporting end masses are frequently used as MEMS/NEMS devices in application areas as diverse as chemical/biosensing, atomic force microscopy, and energy harvesting. This paper presents a new analytical solution for the free vibration of a cantilever with a rigid end mass of finite size. The effects of both translational and rotational inertia as well as horizontal eccentricity of the end mass are incorporated into the model. This model is general regarding the end-mass distribution/geometry and is validated here for the commonly encountered geometries of $\mathrm{T}$ - and $\mathrm{U}$-shaped cantilevers. Comparisons with 3D FEA simulations and experiments on silicon and organic MEMS are quite encouraging. The new solution gives insight into device behavior, provides an efficient tool for preliminary design, and may be extended in a straightforward manner to account for inherent energy dissipation in the case of organicbased cantilevers.
\end{abstract}

\title{
Introduction
}

Dynamic-mode cantilever-based structures supporting end masses (e.g., functionalized paddles, probe tips, and so-called proof or seismic masses) are frequently used as MEMS/NEMS devices in application areas as diverse as chemical/biosensing atomic force microscopy and energy harvesting [1]-[2][3]. To maximize performance of cantilever-based sensors or energy harvesters, the shape of the microstructure need not be limited to the classical parallelepiped geometry. For example, $\mathrm{T}$ - shaped (paddle) or Ushaped beams are now often used. To design such microstructures, different methods can be employed: (a) FEA simulations or (b) analytical modeling. The major drawback of the former is the difficulty in extracting the influence of each design parameter without performing many time-consuming simulations, while in the latter case the solution is often so complicated as to hide underlying relationships. This serves as the motivation for the present study in which a simple analytical formula is derived for replacing an arbitrary end mass with 
an "effective point mass" at the beam tip which incorporates the effects of rotational inertia and eccentricity of the end mass in addition to its translational mass. The utility of the result lies not only in its generality but also in that it may permit one to convert known dynamic solutions for a cantilever with a point mass (e.g., [4]) into solutions applicable to more realistic end masses.

\section{Analytical Model}

\section{A. Problem Statement}

The problem of interest is illustrated in Fig. 1. Our objective is to replace the finite end mass on the cantilever with an effective point mass $M$ eff at the beam tip in order to account for the rotational inertia $J$ and the eccentricity $e$ in addition to the translational inertia $M$. In doing so, we assume that (a) the beam is elastic, prismatic, and monolithic with the end mass; (b) the end mass is rigid; and (c) only horizontal eccentricity (Fig. 1) is considered. We also restrict our attention to the first bending mode, whose shape is assumed to be dominated by the inertial force at the beam tip, i.e., the vibrational shape is taken to be the static shape due to an end force. In addition to the length $L$ and eccentricity $e$ defined in Fig. 1, the following symbols are employed: $I=$ second moment of area of beam cross section; $\bar{m}=$ mass per unit length of beam; $E=$ Young's modulus of the beam material; and $J=$ mass moment of inertia of the end mass about the axis through its center of mass $G$ (for rotation in the plane of Fig. 1 ). The dynamic deflection is denoted by $w(\xi, t)$, where $\xi=x / L$ and $t$ represents time.

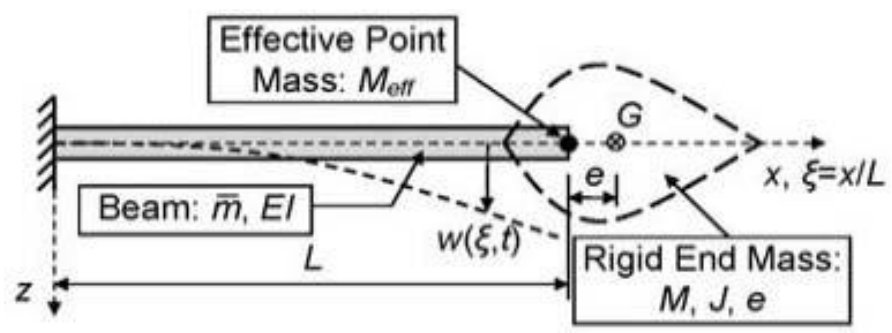

Fig. 1. Schematic of an elastic cantilever with a rigid, eccentric end mass of finite size. The end mass is to be replaced by the effective point mass shown. 


\section{B. Derivation of Effective Point Mass}

Assuming that no mechanical loads external to the structure of Fig. 1 act on the end mass, an equilibrium analysis of the end mass results in the following boundary conditions (BCs) at the end of the beam for the cases of the original finite end mass $(l a, b)$ and its effective point mass counterpart $(2 a, b)$ :

$$
\begin{gathered}
W^{\prime \prime}(1, t)+\frac{J L}{E I} \ddot{W}^{\prime}(1, t)+\frac{M L^{2} e}{E I}\left[\ddot{w}(1, t)+\frac{e}{L} \ddot{w}^{\prime}(1, t)\right]=0, \\
W^{\prime \prime}(1, t)-\frac{M L^{3}}{E I}\left[\ddot{w}(1, t)+\frac{e}{L} \ddot{w}^{\prime}(1, t)\right]=0, \\
W^{\prime \prime}(1, t)=0 \\
W^{\prime \prime}(1, t)-\frac{M_{e f f} L^{3}}{E I} \ddot{w}(1, t)=0
\end{gathered}
$$

where primes and dots denote differentiation with respect to $\xi$ and $t$, respectively. These two sets of BCs may be interpreted as two sets of end loads on the beam. By requiring that the work done by the end loads of $(2 a, b)$ equals that done by those of $(l a, b)$, the "workequivalent" effective point mass becomes

$$
M_{e f f}=M\left[(1+3 \bar{e})+\frac{9}{4}\left(\bar{e}^{2}+\bar{J}\right)\right],
$$

in which $\bar{e} \equiv e / L$ and $\bar{J} \equiv J / M L^{2}$ are the normalized eccentricity and mass moment of inertia of the original finite end mass, respectively. Equation (3) is general in the sense that no specific end mass geometry has been assumed.

A graphical representation of the general result (3) is shown in Fig. 2. This equation and the accompanying figure allow one to estimate the influence of each effect (rotational inertia and eccentricity) on the effective point mass and to calculate the error associated with the cruder approximation of simply replacing an 
eccentric finite mass $M$ with a point mass $M$ placed at the beam tip. In most cases of practical interest the value of $J / M L^{2}$ for the end mass will not exceed 0.2. Therefore, the results of Fig. 2 show that, unless the end mass is concentric with the beam tip (or nearly so), the effective mass will be much more sensitive to the normalized eccentricity parameter than the rotational inertia parameter. For example, for $e / L=0.5$ and $J / M L^{2}=0.2$, Eq. (3) (and Fig. 2) indicate that the effective end mass is 3.51 times the actual end mass, with $87 \%$ of this factor being due to the eccentricity effect and only $13 \%$ due to the rotational inertia.

\section{Special Cases: t-and u-Shaped Cantilevers}

In many cases the device is fabricated with a rectilinear geometry such as that of aT-beam or a U-beam (Figs. 3, 4), in which case Eq. (3) reduces to

$$
M_{e f f}=M\left[1+\frac{3}{2}\left(\frac{L_{0}}{L}\right)+\frac{3}{4}\left(\frac{L_{0}}{L}\right)^{2}+\frac{3}{16}\left(\frac{h_{0}}{L}\right)^{2}\right]
$$

where $L_{0}$ and $h_{0}$ are the length and thickness of the head. This expression may be used in place of $M$ in existing solutions for a cantilever with a concentrated tip mass $M$. , thus accounting for the eccentricity and rotational inertia of the head mass.

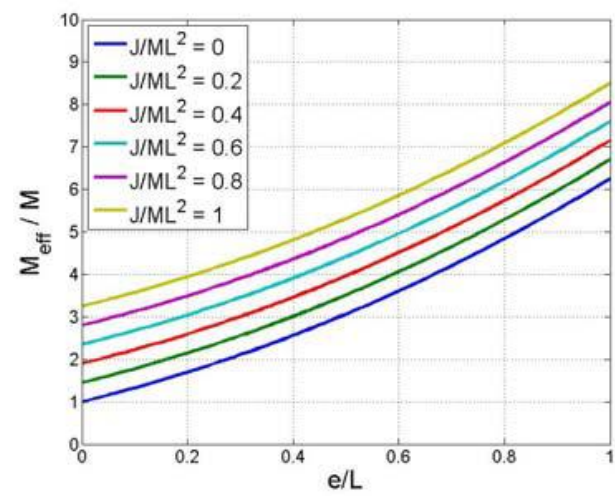

Fig. 2. Plot of general equation (3) showing dependence of normalized effective mass on normalized eccentricity and rotational inertia parameters. 
NOT THE PUBLISHED VERSION; this is the author's final, peer-reviewed manuscript. The published version may be accessed by following the link in the citation at the bottom of the page.

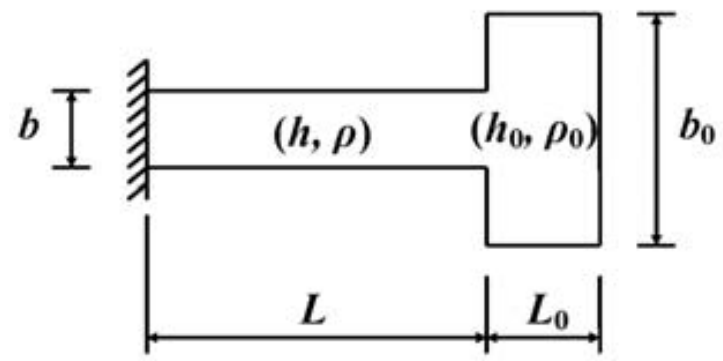

Fig. 3. Plan view and notation for T-shaped cantilever. (Thicknesses and densities are listed parenthetically.)

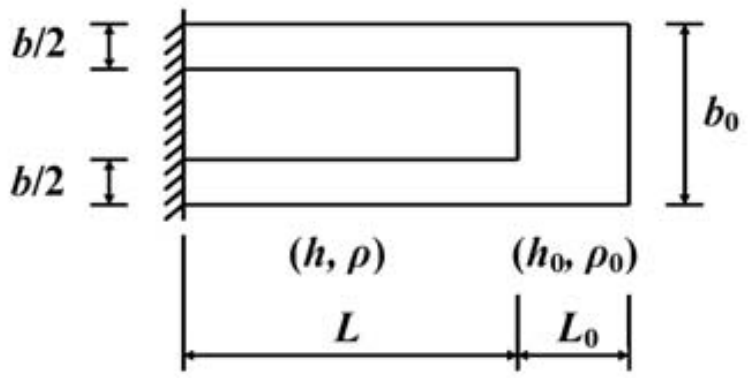

Fig. 4. Plan view and notation for U-shaped cantilever. (Thicknesses and densities are listed parenthetically.)

\section{Illustrative Examples}

\section{A. Comparison with 3d Fea Results for t-Shaped} Devices

To demonstrate the use of result (4) we estimate the fundamental frequency $f$ of aT-shaped polymer-based energy harvester having a polymer stem with $(h, b, L)=(10,300,600)$ $\mu \mathrm{m}, \rho=1000 \mathrm{~kg} / \mathrm{m}^{3}, E=4 \mathrm{GPa}$; and a relatively dense and stiff head characterized by $\left(h_{0}, b_{0}, L_{0}\right)=(50,1000,500) \mu \mathrm{m}, \rho_{0}=4000 \mathrm{~kg} / \mathrm{m}^{3}, E_{0}=40$ GPa. A benchmark value of $f=350.7 \mathrm{~Hz}$ was obtained from a finite element analysis using a mesh of higher-order 3D brick elements and assuming Poisson's ratio values of $\mathrm{v}=\mathrm{v}_{0}=0.25$ for the stem and head materials, respectively. The point mass solution (e.g., [4]) with $I=b h^{3} / 12$ (and $M=100 \mu \mathrm{g}$ for the head mass) gives 
NOT THE PUBLISHED VERSION; this is the author's final, peer-reviewed manuscript. The published version may be accessed by following the link in the citation at the bottom of the page.

$$
f=\frac{1}{2 \pi} \sqrt{\frac{3 E I}{\bar{m} L^{4}\left(\frac{M}{\bar{m} L}+0.2427\right)}}=591.8 \mathrm{HZ},
$$

which, as expected, is a very poor estimate (69\% high) due to the large head size and, thus, significant eccentricity. However, if we replace $M$ in (5) with $M_{\text {eff }}=2.772 M=277.2 \mu \mathrm{g}$ as given by (4) to account for eccentricity and rotational inertia of the head, we achieve an excellent estimate of $f=356.0 \mathrm{~Hz}$, which is only $1.5 \%$ larger than the 3D FEA result.

Other comparisons have been made for other T-shaped devices using the same procedure. The geometric and material parameters for these cases are listed in Table I and the corresponding results in Table II. (The previous example is Case 1.) Note that the energy harvester of Case 2 consists of a Si T-beam of uniform 10- $\mu$ m thickness with an additional 50-urn layer of another material deposited on the head area, while Case 3 is a homogeneous Si device of uniform thickness used for sensing applications. The finite element analyses for Cases 2 and 3 consider the anisotropic nature of the silicon. In all cases the bottom surfaces of the beam and head are coplanar. The results of Table II indicate that the simple analytical approach proposed here provides very good estimates of the natural frequency as determined by 3D FEA, even when the latter accounts for the complicating effects of anisotropy, head deformation, and vertical eccentricity of the head. Moreover, the new approach yields significant improvements over the cruder approach of lumping the actual end mass $(\mathrm{M})$ at the beam tip. The frequency estimates of the proposed approach are slightly stiff since the rigid-head assumption neglects head deformation that will in actuality result in higher effective mass and lower effective stiffness, both of which will cause a reduction in natural frequency. This observation is consistent with the fact that the largest error based on the new formula ( $5.3 \%$ ) occurs for the case of a uniform-thickness device, which is expected to involve less rigid behavior of the head in comparison with the other two cases in which the head (proof mass of the device) is much thicker than the beam portion. 
Table I. Geometric and material parameters of the T-shaped devices used for 3D fea vs. Analytical modeling comparisons

\begin{tabular}{|c|c|c|c|}
\hline $\begin{array}{l}\text { Case No. } \\
\text { and } \\
\text { Description }\end{array}$ & $\begin{array}{c}\text { 1: } \\
\text { Polymer- } \\
\text { based } \\
\text { Energy } \\
\text { Harvester }\end{array}$ & $\begin{array}{c}2: \\
\text { Silicon-based } \\
\text { Energy } \\
\text { Harvester }^{a}\end{array}$ & $\begin{array}{c}\text { 3: } \\
\text { T-shaped } \\
\text { Silicon } \\
\text { Sensor, } \\
\text { Uniform } \\
\text { Thickness }\end{array}$ \\
\hline$L$ [um] & 600 & 600 & 500 \\
\hline$b[\mu \mathrm{m}]$ & 300 & 300 & 200 \\
\hline$h[\mu \mathrm{m}]$ & 10 & 10 & 5 \\
\hline$\rho\left[\mathrm{kg} / \mathrm{m}^{3}\right]$ & 1000 & 2330 & 2330 \\
\hline$E$ [GPa] & 4 & \multirow{2}{*}{\multicolumn{2}{|c|}{ orthotropic $^{b}$}} \\
\hline $\mathbf{v}$ & 0.25 & & \\
\hline$L_{0}[\mu \mathrm{m}]$ & 500 & 500 & 500 \\
\hline$b_{0}[\mu \mathrm{m}]$ & 1000 & 1000 & 1000 \\
\hline$h_{0}[\mu \mathrm{m}]$ & 50 & $60^{c}$ & 5 \\
\hline$\rho_{0}\left[\mathrm{~kg} / \mathrm{m}^{3}\right]$ & 4000 & $4271.7^{d}$ & 2330 \\
\hline$E_{\theta}[\mathrm{GPa}]$ & 40 & 169 & \multirow{2}{*}{ orthotropic ${ }^{b}$} \\
\hline$v_{\theta}$ & 0.25 & 0.25 & \\
\hline
\end{tabular}

${ }^{a} 10-\mu \mathrm{m}$ thick Si T-beam with additional $50-\mu \mathrm{m}$ of head material. ${ }^{b} \mathrm{Si}$ modeled as orthotropic in FE model with beam aligned with $<110>$ direction (properties from [5]); $E=169 \mathrm{GPa}$ in analytical models. ctotal head thickness $=10 \mu \mathrm{m}$ (Si base) plus $50 \mu \mathrm{m}$ (additional head material);

${ }^{d}$ density of additional head material is taken as $4660 \mathrm{~kg} / \mathrm{m}^{3}$, resulting in average head density of $4271.7 \mathrm{~kg} / \mathrm{m}^{3}$.

Table II. Natural frequency for T-beams: 3D FEA, classical point-mass model, and new analytical model

\begin{tabular}{|c|c|c|c|}
\hline $\begin{array}{c}\text { Case No. } \\
\text { and } \\
\text { Description }\end{array}$ & $\begin{array}{c}\text { 1: } \\
\text { Polymer- } \\
\text { based } \\
\text { Energy } \\
\text { Harvester }\end{array}$ & $\begin{array}{c}\text { 2: } \\
\text { Silicon- } \\
\text { based } \\
\text { Energy } \\
\text { Harvester }\end{array}$ & $\begin{array}{c}\text { 3: } \\
\text { T-shaped } \\
\text { Silicon } \\
\text { Sensor, } \\
\text { Uniform } \\
\text { Thickness }\end{array}$ \\
\hline $\begin{array}{c}f[\mathrm{~Hz}] \\
\text { 3D FEA } \\
\text { (benchmark) }\end{array}$ & 350.7 & 1985 & 3171 \\
\hline $\begin{array}{c}f \text { [Hz] } \\
\text { Point-mass } \\
\text { Model [4] } \\
\text { (\% error) }\end{array}$ & 591.8 & 3392 & 5920 \\
\hline $\begin{array}{c}f[\text { Hz] } \\
(69 \% \text { high) }\end{array}$ & $(71 \%$ high) & $(87 \%$ high) \\
\hline $\begin{array}{c}\text { Present Model } \\
\text { (Eq. 4 or 5) } \\
\text { (\% error) }\end{array}$ & $\begin{array}{c}356.0 \\
(1.5 \% \text { high) }\end{array}$ & $\begin{array}{c}2042 \\
(2.9 \% \text { high) }\end{array}$ & $\begin{array}{c}3338 \\
(5.3 \% \text { high) }\end{array}$ \\
\hline
\end{tabular}

2014 IEEE Sensors Proceedings, (2014): pg. 1648-1651. DOI. This article is @ Institute of Electrical and Electronics Engineers (IEEE) and permission has been granted for this version to appear in e-Publications@Marquette. Institute of Electrical and Electronics Engineers (IEEE) does not grant permission for this article to be further copied/distributed or hosted elsewhere without the express permission from Institute of Electrical and Electronics Engineers (IEEE). 


\section{B. Comparison with Experiments on Silicon Microstructures}

Silicon cantilevers with electromagnetic actuation and piezoresistive readout have been fabricated and tested. These included prismatic cantilevers as well as devices of $\mathrm{T}$ - and $\mathrm{U}$-shaped geometries, all of which consisted of a $5-\mu \mathrm{m}$ thick Si layer and a 200$\mathrm{nm} \mathrm{SiO} 2$ later. Actuation circuitry comprised an aluminum path of 500$\mathrm{nm}$ thickness and $10-\mu \mathrm{m}$ width. Resonant frequency measurements for the uniform beams, involving four different geometries (total sample size of 10) whose lengths and widths varied from 1 to $2 \mathrm{~mm}$ and 0.4 to $1 \mathrm{~mm}$, respectively, showed that the error of the analytical estimates ranged from $7 \%$ low to $2 \%$ high. This comparison provided validation of the Si properties ( $E=169 \mathrm{GPa}, \rho=2330 \mathrm{~kg} / \mathrm{m}$ ') to be used for modeling the $\mathrm{T}$ - and U-shaped devices.

Resonant frequency test results for four device types of nonuniform width ( 2 T's and 2 U's with dimensions as indicated in Table III) are listed in Table IV along with the modeling results with and without the effects of eccentricity and rotational inertia of the end mass. (Both models accounted for the extra mass due to the $\mathrm{SiO}_{2}$ and the A1.). The comparisons show that (a) including the extra end mass effects via the new model reduces the modeling errors significantly; (b) the estimates of the new model for the smaller-head devices ( $U 1$ and $\mathrm{T}$ 1) are very good, lying within the range of measured frequencies, although tending to be slightly stiff; and (c) the newmodel predictions for cases U3 and T2 (larger heads), while good in some cases, include some frequencies that are up to $25 \%$ too high. Observations (b) and (c) are consistent with the fact that the model is based on a rigid-head assumption; therefore, since head deformation will result in a lower (higher) system stiffness (mass), we expect the theory to slightly overestimate the frequency data, with the error increasing for larger (i.e., more flexible) end-mass footprints. 
NOT THE PUBLISHED VERSION; this is the author's final, peer-reviewed manuscript. The published version may be accessed by following the link in the citation at the bottom of the page.

Table III. Data for the t-and u-shaped silicon cantilevers

\begin{tabular}{|c|c|c|c|c|c|}
\hline $\begin{array}{c}\text { Device } \\
\text { Designation }\end{array}$ & $\begin{array}{c}\boldsymbol{L} \\
{[\mathbf{\mu m}]}\end{array}$ & $\begin{array}{c}\boldsymbol{b} \\
{[\mathbf{\mu m}]}\end{array}$ & $\begin{array}{c}\boldsymbol{h}=\boldsymbol{h}_{\mathbf{0}} \\
{[\mathbf{\mu m}]}\end{array}$ & $\begin{array}{c}\boldsymbol{L}_{\mathbf{0}} \\
{[\mathbf{\mu m}]}\end{array}$ & $\begin{array}{c}\boldsymbol{b}_{\mathbf{0}} \\
{[\mathbf{\mu m}]}\end{array}$ \\
\hline $\mathrm{U} 1$ & 666 & 500 & 5 & 334 & 1000 \\
\hline $\mathrm{U} 3$ & 333 & 200 & 5 & 667 & 1000 \\
\hline $\mathrm{T} 1$ & 500 & 200 & 5 & 500 & 1000 \\
\hline $\mathrm{T} 2$ & 250 & 200 & 5 & 750 & 1000 \\
\hline
\end{tabular}

Table IV. Resonant frequency for t-and u-beams: measurement, classical point-mass model, and new analytical model

\begin{tabular}{|c|c|c|c|}
\hline $\begin{array}{c}\text { Device } \\
\text { Type } \\
\text { (sample } \\
\text { size) }\end{array}$ & $\begin{array}{c}f[\mathrm{~Hz}] \\
\text { measurement } \\
\text { range }\end{array}$ & $\begin{array}{c}f[\mathrm{~Hz}] \\
\text { Point-mass } \\
\text { Model [4] } \\
\text { (\% error) }\end{array}$ & $\begin{array}{c}f[\mathrm{~Hz}] \\
\text { Present Model } \\
\text { (Eq. 4 or 5) } \\
(\% \text { error)] }\end{array}$ \\
\hline $\begin{array}{c}\text { U1 } \\
(2)\end{array}$ & $4460-5046$ & $\begin{array}{c}6701 \\
(33 \%-50 \%)\end{array}$ & $\begin{array}{c}5044 \\
(-0.05 \%-13 \%)\end{array}$ \\
\hline U3 & $3114-3320$ & $\begin{array}{c}9315 \\
(181 \%-199 \%)\end{array}$ & $\begin{array}{c}3552 \\
(7 \%-14 \%)\end{array}$ \\
\hline (2) & $2938-3395$ & $\begin{array}{c}5779 \\
(70 \%-97 \%)\end{array}$ & $\begin{array}{c}3256 \\
(-4 \%-11 \%)\end{array}$ \\
\hline T1 & $3133-3525$ & $\begin{array}{c}13557 \\
(285 \%-333 \%)\end{array}$ & $\begin{array}{c}3901 \\
(11 \%-25 \%)\end{array}$ \\
\hline T2 & & & \\
$(7)$ & & &
\end{tabular}

\section{Comparison with Experiments: u-Shaped Organic Devices}

U-shaped piezoresistive organic cantilevers have been fabricated using a new two-step fabrication process that is quick, extremely lowcost and very environmentally friendly [6]. Initially, a piezoresistive solution made of CNT/SU8 is spin-coated onto either a polyethylene terephthalate (PET) sheet of 100- $\mu \mathrm{m}$ thickness, a $50-\mu \mathrm{m}$ sheet of polyethylene naphtalate (PEN), or a $200-\mu m$ paper (Powercoat $($ ) sheet. Subsequently the resonators are simply patterned using a cutting plotter machine (Graphtec Craft ROBO Pro). SEM images of the PET-based microstructure are shown in Fig. 5. 
NOT THE PUBLISHED VERSION; this is the author's final, peer-reviewed manuscript. The published version may be accessed by following the link in the citation at the bottom of the page.
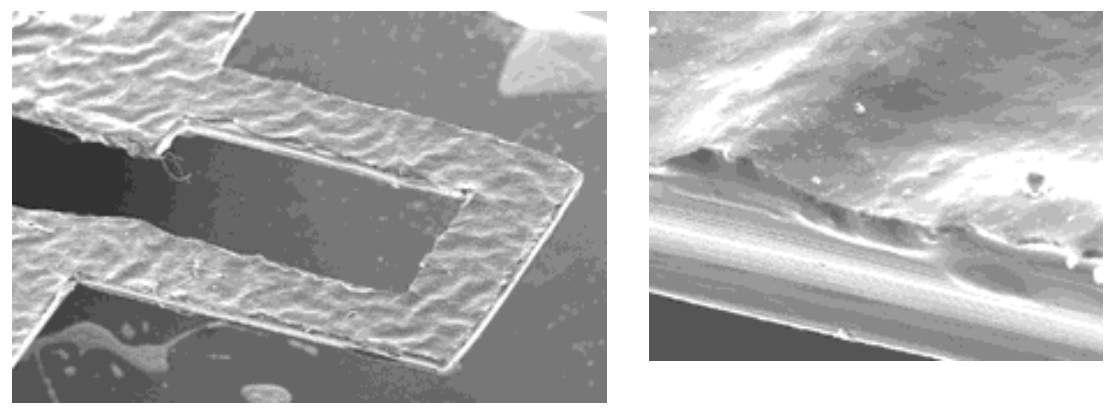

Fig. 5.

SEM images of a fabricated organic resonator (pet-cnt/su8)

The mechanical behavior of the bilayer system of Fig. 5 may be described by an effective complex modulus, " $E+j E$ ", corresponding to a gross section having the same total thickness and width. Taking $I=b\left(h_{1}+h_{2}\right)^{3} / 12$, where $h_{1}$ and $h_{2}$ denote the thicknesses of the substrate and nanocomposite layers, respectively, and using the dimensions and (through-thickness) average densities of the three $U$ shaped structures listed in Table $\mathrm{V}$, measured values of resonant frequency may be converted to values of the effective storage modulus $E$ by employing analytical expressions (4) and (5). (The average densities in the table are taken as the densities of the substrate due to its dominant thickness.) In doing so $M$ eff replaces $M$ and $E$ replaces $E$ in (5). The effective loss modulus " $E$ " is obtained by assuming that the measured quality factor $Q$ is due solely to the viscoelastic losses, i.e., " $Q=E^{\prime} / E^{\prime}$ [7]. The material properties determined by this method have been compared with those based on dynamic mechanical analysis (DMA) in Table VI and show excellent agreement for the storage modulus and good agreement for the material dissipation as characterized by the effective loss tangent ( $\tan \delta=E^{\prime \prime} / E$ ), thus providing some further validation for the analytical modeling.

Table V. Data for the u-shaped organic cantilevers

\begin{tabular}{|c|c|c|c|c|c|c|}
\hline $\begin{array}{c}\text { CNT/SU8 } \\
\text { on }\end{array}$ & $\begin{array}{c}\boldsymbol{L} \\
{[\boldsymbol{\mu} \mathbf{m}]}\end{array}$ & $\begin{array}{c}\boldsymbol{b} \\
{[\boldsymbol{\mu m}]}\end{array}$ & $\begin{array}{c}\boldsymbol{h}=\boldsymbol{h}_{\mathbf{0}} \\
{[\boldsymbol{\mu \mathbf { m } ]}}\end{array}$ & $\begin{array}{c}\boldsymbol{L}_{\mathbf{0}} \\
{[\boldsymbol{\mu \mathbf { m } ]}]}\end{array}$ & $\begin{array}{c}\boldsymbol{b}_{\mathbf{0}} \\
{[\boldsymbol{\mu \mathbf { m } ]}]}\end{array}$ & $\begin{array}{c}\boldsymbol{p}=\boldsymbol{\rho}_{\mathbf{0}} \\
{\left[\mathbf{k} \mathbf{g} \mathbf{m}^{\mathbf{3}}\right]}\end{array}$ \\
\hline PET & 2400 & 700 & 118 & 400 & 1600 & 1380 \\
\hline PEN & 2900 & 600 & 64 & 300 & 2200 & 1360 \\
\hline Paper & 3000 & 600 & 218 & 375 & 2200 & 1000 \\
\hline
\end{tabular}

2014 IEEE Sensors Proceedings, (2014): pg. 1648-1651. DOI. This article is @ Institute of Electrical and Electronics Engineers (IEEE) and permission has been granted for this version to appear in e-Publications@Marquette. Institute of Electrical and Electronics Engineers (IEEE) does not grant permission for this article to be further copied/distributed or hosted elsewhere without the express permission from Institute of Electrical and Electronics Engineers (IEEE). 
NOT THE PUBLISHED VERSION; this is the author's final, peer-reviewed manuscript. The published version may be accessed by following the link in the citation at the bottom of the page.

Table VI. Measured effective storage modulus ( $\left.e^{\prime}\right)$, loss modulus $\left(e^{\prime \prime}\right)$ and loss tangent (tan 6) AL room temperature for bimorph materials of cnt/su8 nanocomposite deposited onto pet, pen and paper substrates

\begin{tabular}{|c|c|c|c|c|c|c|}
\cline { 2 - 7 } \multicolumn{1}{c|}{} & \multicolumn{2}{c|}{$E^{\prime}$ '(GPa) } & \multicolumn{2}{c|}{$E^{\prime \prime}$ (MPa) } & \multicolumn{2}{c|}{$\tan \delta=E^{\prime \prime} / E^{\prime}$} \\
\hline $\begin{array}{c}\text { CNT/SU8 } \\
\text { on }\end{array}$ & DMA & MEMS & DMA & MEMS & DMA & MEMS \\
\hline PET & 4.43 & 4.88 & 131 & 212 & 0.030 & 0.043 \\
\hline PEN & 2.90 & 2.80 & 290 & 187 & 0.100 & 0.067 \\
\hline Paper & 4.33 & 4.13 & 625 & 376 & 0.144 & 0.091 \\
\hline
\end{tabular}

\section{Conclusions}

A new analytical formula has been derived that enables one to treat a cantilever-supported end mass of finite size and arbitrary shape with an effective point mass positioned at the cantilever tip. The simple expression includes not only the translational inertia (mass) of the end mass, but also its rotational inertia and horizontal eccentricity effects. The proposed effective tip mass approach permits known dynamic solutions for a cantilever with a point mass to be easily mapped into corresponding solutions that incorporate these additional effects, which are often significant. To illustrate the method, analytical estimates of the natural frequencies of three T-shaped devices were compared with 3D FEA results, the latter including anisotropy, head deformation, and vertical eccentricity effects; the agreement was quite good with errors not exceeding $5 \%$. Frequency estimates based on the new approach were also compared with experimental data on Si-based $\mathrm{U}$-and T-shaped structures, showing significant improvements over the classical point-mass approach that ignores eccentricity and rotational inertia. Finally, the new method was implemented as an alternative approach for estimating the effective viscoelastic properties of bilayer, polymeric composites using $U$-shaped specimens, the results being consistent with measurements based on dynamic mechanical analysis and thereby providing further validation of the proposed analytical formula.

\section{Acknowledgments}

This work was partially supported by the French National Agency (ELENA project ANR-12-NANO-00203), by IdEx Bordeaux, by Labex AMADEus and by Andra. The authors thank Liviu Nicu, Fabrice Mathieu, Thierry Leichle

2014 IEEE Sensors Proceedings, (2014): pg. 1648-1651. DOI. This article is @ Institute of Electrical and Electronics Engineers (IEEE) and permission has been granted for this version to appear in e-Publications@Marquette. Institute of Electrical and Electronics Engineers (IEEE) does not grant permission for this article to be further copied/distributed or hosted elsewhere without the express permission from Institute of Electrical and Electronics Engineers (IEEE). 
NOT THE PUBLISHED VERSION; this is the author's final, peer-reviewed manuscript. The published version may be accessed by following the link in the citation at the bottom of the page.

and Laurent Mazenq from LAAS-CNRS (Toulouse, France) for the silicon cantilever fabrication.

\section{Footnotes}

${ }^{1} 10-\mu \mathrm{m}$ thick Si T-beam with additional $50-? \mathrm{~m}$ of head material.

${ }^{2} \mathrm{Si}$ modeled as orthotropic in FE model with beam aligned with $<110>$ direction (properties from [5]); E=169 GPa in analytical models.

${ }^{3}$ total head thickness $=10 \mu \mathrm{m}$ (Si base) plus $50 \mu \mathrm{m}$ (additional head material);

${ }^{4}$ density of additional head material is taken as $4660 \mathrm{~kg} / \mathrm{m}^{3}$, resulting in average head density of $4271.7 \mathrm{~kg} / \mathrm{m}^{3}$.

\section{References}

1. P.S. Waggoner, H.G. Craighead, "The relationship between material properties device design and the sensitivity of resonant mechanical sensors", J Appl. Phys., vol. 105, pp.054306, 2009

2. Y. Song, B. Bhushan, "Finite-element vibration analysis of tapping-mode atomic force microscopy in liquid", Ultramicroscopy, vol. 107, pp.10951104,2007

3. S. Beeby, N. White, Energy Harvesting for Autonomous Systems, Artech House, 2010

4. R.D. Blevins, Formulas for Natural Frequency and Mode Shape, Van Nostrand Reinhold Company Inc., 1979

5. M.A. Hopcroft, W.D. Nix, T.W. Kenny, "What is the Young's modulus of silicon?", JMEMS, vol. 19, pp.229-238, 2010

6. E. Lemaire, Contribution au developpement de microcapteurs integres de viscoelasticite de fluides, 08, 2013

7. K.Y. Yasumura, T.D. Stowe, E.M. Chow, T. Pfafman, T.W. Kenny, B.C. Stipe, D. Rugar, "Quality Factors in Micron-and Submicron-Thick Cantilevers", JMEMS, vol. 9, pp.117-125, 2000

2014 IEEE Sensors Proceedings, (2014): pg. 1648-1651. DOI. This article is @ Institute of Electrical and Electronics Engineers (IEEE) and permission has been granted for this version to appear in e-Publications@Marquette. Institute of Electrical and Electronics Engineers (IEEE) does not grant permission for this article to be further copied/distributed or hosted elsewhere without the express permission from Institute of Electrical and Electronics Engineers (IEEE). 